\title{
Plant lectins: the ties that bind in root symbiosis and plant defense
}

\author{
Peter L. De Hoff · Laurence M. Brill • Ann M. Hirsch
}

Received: 12 September 2008 / Accepted: 10 May 2009 / Published online: 2 June 2009

(C) The Author(s) 2009. This article is published with open access at Springerlink.com

\begin{abstract}
Lectins are a diverse group of carbohydratebinding proteins that are found within and associated with organisms from all kingdoms of life. Several different classes of plant lectins serve a diverse array of functions. The most prominent of these include participation in plant defense against predators and pathogens and involvement in symbiotic interactions between host plants and symbiotic microbes, including mycorrhizal fungi and nitrogen-fixing rhizobia. Extensive biological, biochemical, and molecular studies have shed light on the functions of plant lectins, and a plethora of uncharacterized lectin genes are being revealed at the genomic scale, suggesting unexplored and novel diversity in plant lectin structure and function. Integration of the results from these different types of research is beginning to yield a more detailed understanding of the function of lectins in symbiosis, defense, and plant biology in general.
\end{abstract}

Keywords Saccharide recognition - MAMPs · PRRs . Agglutination

Communicated by S. Hohmann.

P. L. De Hoff · L. M. Brill · A. M. Hirsch $(\bowtie)$

Department of Molecular, Cell and Developmental Biology, University of California, Los Angeles, CA 90095, USA e-mail: ahirsch@ucla.edu

URL: http://www.mcdb.ucla.edu/Research/Hirsch/

P. L. De Hoff · A. M. Hirsch

Molecular Biology Institute, University of California,

Los Angeles, CA 90095, USA

Present Address:

L. M. Brill

Burnham Institute for Medical Research,

10901 North Torrey Pines Road, La Jolla, CA 92037, USA

\section{Introduction}

Lectins are defined as proteins that reversibly and nonenzymatically bind specific carbohydrates. They have been the subjects of numerous reviews (Lord 1985; Barondes 1988; Pusztai 1991; Sharon and Lis 1989, 2004; Barre et al. 2002; Komath et al. 2006). Peumans and Van Damme (1995) extended the original definition of lectins to include any protein having at least one noncatalytic domain that binds reversibly to a specific carbohydrate, whether it is a mono- or oligosaccharide.

Lectins are found in cells, membranes, and secretomes of organisms from all kingdoms of life, and tolerate a degree of binding-pocket sequence variation for ligand specificity rivaling that of immunoglobins (McMahon et al. 2005). Carbohydrates are a far more diverse group of molecules than proteins, owning to the variability in their constituent saccharide monomers. Beyond the variation found in the carbon backbone length of the monomer, anomericity, side group orientation and substitution, the carbohydrate assembly often branches, further complicating structure. Because of this diversity, each cell, plasma membrane, or intracellular organelle has a characteristic carbohydrate "coat", i.e. cell wall (plant) or glycocalyx (animal) and glycosylated biological membranes, which can potentially be recognized by specific lectins. Carbohydrate residues on the exterior of a cell are often bound by a specific lectin or a small group of lectins, and as such lectins have been used as histochemical reagents to label mammalian cells, for example, to trace neuronal extensions (Sharon and Lis 1990). Similarly, some of the most common and productive uses of lectin carbohydrate binding specificity has been their application in identifying blood serotypes, preparation of bone marrow for transplantation, mammalian tissue cell types, and identification of stem cells in vitro (Sharon and 
Lis 2004; Venable et al. 2005; Komath et al. 2006; Wearne et al. 2006).

Because of their diversity, classifying lectins into families is a challenge. Lectin classification is still evolving, and general agreement has not been achieved yet. Looking at the lectins as a whole, Arason (1996) proposed six families based on comparisons of the carbohydrate recognition domains (CRD): (1) legume lectins, (2) cereal lectins, (3) P-, (4) S-, and (5) C-type lectins, and (6) the pentraxins. The first two are found in plants whereas the others are more typical of animals.

The plant lectins were previously classified into seven families based on the CRDs: amaranthins, Cucurbitaceae phloem lectins, lectins with hevein domain(s), jacalinrelated lectins, legume lectins, mannose-binding lectins from monocots, and type-2 ribosome-inactivating proteins (Van Damme et al. 2004). For example, the legume (Canavalia ensiformis) lectin Concanavalin A (ConA) binds glucose/mannose residues; soybean (Glycine max) agglutinin (SBA), also known as soybean lectin (SBL), binds $N$ acetyl-D-galactosamine/galactose; gorse (Ulex europaeus) lectin (UEA1) binds L-fucose; and the hevein-domain cereal lectin wheat germ agglutinin (WGA) binds $N$-acetylD-glucosamine. More recently Van Damme et al. (2008) updated their CRD-based lectin classification scheme from 7 to 12 families that encompass nearly all known and certainly all well characterized plant lectins. This new system incorporates sequence and structural homology as well as evolutionary relatedness to classify the plant lectins. Moreover, these recent studies show that previously reported carbohydrate-binding affinities are sometimes misleading for lectin classification, because lectins, as determined by glycoarray analyses, generally show higher binding affinities to complex oligosaccharides than to simple oligosaccharides or monomers (Van Damme et al. 2008; Xia et al. 2005). For this reason, the traditional methods of carbohydrate monomer-based lectin classification are being supplanted by the more informative homology-based systems.

The amino acid residues that form the CRD are highly conserved in legume lectins. These residues are critical for coordinating metals $\left(\mathrm{Ca}^{2+}\right.$ and $\left.\mathrm{Mn}^{2+}\right)$ and for forming hydrophobic pockets, as well as being important for carbohydrate binding (Pusztai 1991). However, while lectins generally have fairly low affinities to their cognate carbohydrates ( $K_{\mathrm{D}}$ 's in the high $\mu \mathrm{M}$ to low $\mathrm{mM}$ range), they are frequently multivalent, leading to high-avidity binding in vivo. Interestingly, the hydrophobic pockets in lectins allow these proteins to not only bind sugar monomers or their oligomers via backbone interactions, but also small molecules such as auxin or cytokinin (see Table 2 in Komath et al. 2006). Although legume lectins show only weak binding to phytohormones other than adenine
(Roberts and Goldstein 1983; Gegg et al. 1992), cereal lectins such as WGA bind a larger number of phytohormones-adenine-related cytokinins, abscisic acid, and gibberellic acid—with high affinities (Bogoeva et al. 2004). This binding is proposed to serve as a means of regulating free versus stored phytohormones in different tissues (Bogoeva et al. 2004).

Other classification schemes besides those based on the CRDs also exist such as those based on various structural features of lectins (Sharon and Lis 2004), or schemes that form metagroups based on evolutionary relationships within subgroups (Varki et al. 2008). The field of lectin nomenclature continues to develop as new sequence and functional data are collected, expanding and refining the lectin family. For instance, the S-type lectins were renamed "galectins" due to lack of universal thiol group dependency, and the C-type lectins were split to denote the selectins (P-, E-, L- subtypes), collectins, and endocytic lectins. Lectin types B-, E-, F-, G-, N-, M-, P-, R-, T-, W-, X-, are in use or have been proposed.

Of the plant lectins, the legume lectins as a group have been the most extensively studied (Van Damme et al. 2008). The three-dimensional structure of ConA was the first to be elucidated among legume lectins (Edelman et al. 1972). Many other lectins have since been purified and their structures solved, and some have been co-crystallized with their ligands such as the Lens culinaris seed lectin monomer (Fig. 1a) and the Lotus tetragonolobus seed lectin tetramer (Fig. 1b). When crystallized, legume lectins generally consist of two or four $25-30 \mathrm{kDa}$ subunits, which are dome-shaped and consist largely of antiparallel $\beta$-sheets. These are generally arranged such that there is a series of ca. 6 parallel $\beta$-sheets or $\beta$-strands forming an interacting face for multimerization; a group of ca. 7 anti-parallel $\beta$-sheets that have a generally concave shape and form the carbohydrate binding domain, as well as the metal cofactor binding pockets; and a shorter $\beta$-sheet on the "top" that connects the parallel and anti-parallel $\beta$-sheets (Vijayan and Chandra 1999). The subunits may consist of identical chains as for phytohemagglutinin (PHA; Phaseolus vulgaris L. lectin) or are distinct, as exemplified by the $\alpha$-(smaller) and $\beta$-(larger) subunits of Pisum sativum L. lectin (PSL) (Lioi et al. 2006). Overall, the legume lectins (L-type) whose structures are known exhibit a similar protein-folding pattern, thus exhibiting three-dimensional structural conservation. In contrast to the generally conserved legume lectin fold structures, the major cereal lectins, a less extensively characterized family of proteins than the legume lectins (Sharon 1993; Van Damme et al. 2008), are homodimers comprised of two subunits of ca. $18 \mathrm{kDa}$. In addition, the cereal lectinsWGA, rye, barley, and rice lectins — are highly homologous to one another. Rye and barley lectins are able to heterodimerize with WGA (Etzler 1995). 

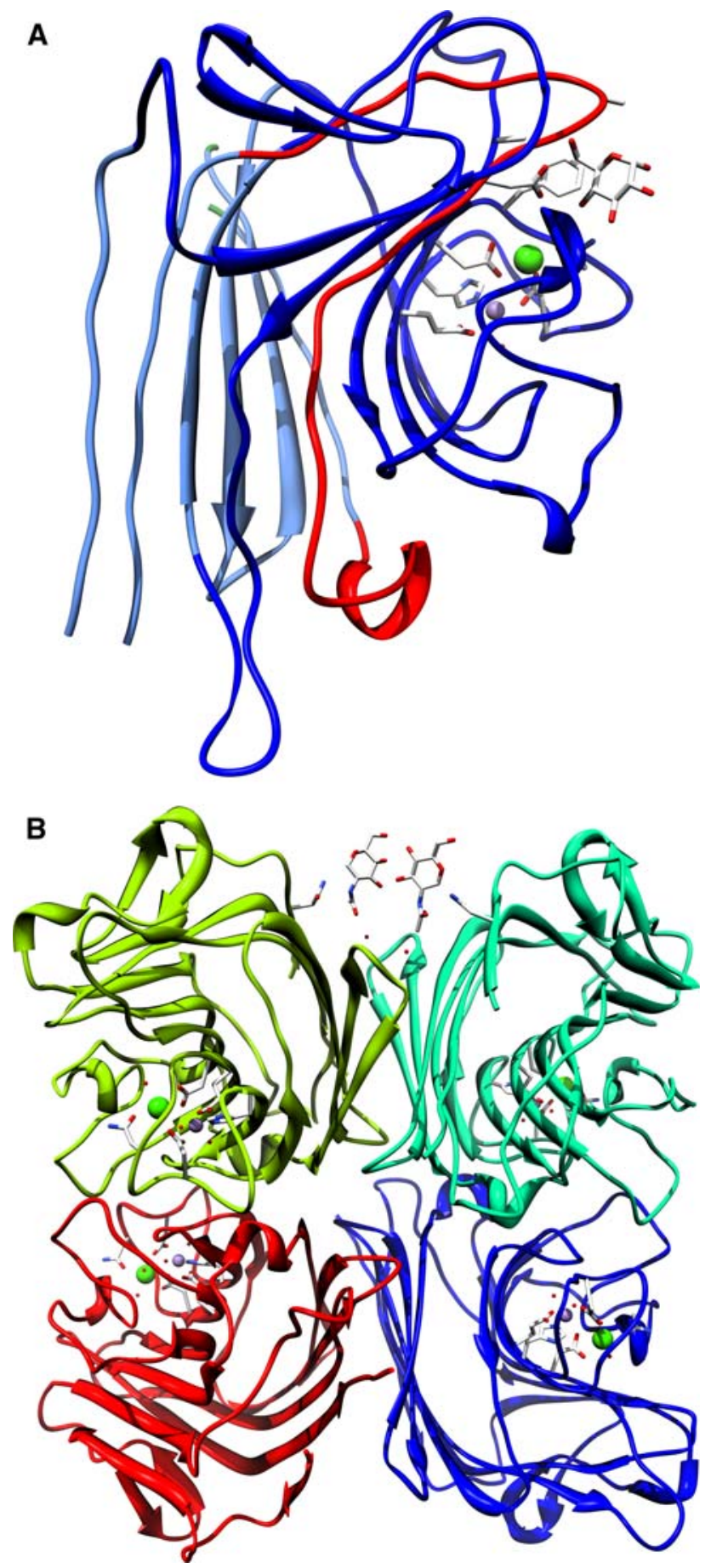

Inside of the plant cell, as in other eukaryotic cells, some lectins associate with the ER (for example, calreticulin and calnexin) and are involved in surveillance mechanisms for proper protein folding (Banerjee et al. 2007). However, there is a dearth of evidence for the function of lectins in the cytoplasm or at the plasma membrane (Van Damme et al. 2004). Although plant nuclear and cytoplasmic lectins are known, they are generally not ubiquitous and are induced to relatively low levels of expression following
4 Fig. 1 Lectin structures. a Structural model of the seed lectin monomer (doi:10.2210/pdb1LEM/pdb) from Lens culinaris, derived from co-crystallization of the protein and its ligand, at $3.00 \AA$ resolution. This glucose/mannose binding lectin (see Loris et al. 1994) illustrates the typical L-legume fold with the flat $\beta$-sheet and $\beta$-strand dimerization interface (light blue, left side) and the structural elements (dark blue, right side) showing the " $\mathrm{C}$ " cup fold containing the sugar/metal co-factor interaction domains. Typical to most L-lectins is the direct interaction between the calcium co-factor and the target carbohydrate inside of the structurally conserved binding pocket. Atypical among most L-lectins (except PSL) is the internal proteolytic site on a portion of the polypeptide, shown as a red (middle) strand. This sequence makes up a component of the dimerization face as well as a support structure for the carbohydrate-binding domain. b Structural model of the homotetramer Lotus tetragonolobus seed lectin (LTA) (doi:10.2210/pdb2EIG/pdb), derived from co-crystallization of the protein and its ligands, at $2.00 \AA$ resolution. This fucose-binding (see Moreno et al. 2008) lectin (here shown with $N$-acetyl-glucosamine residues) is structurally very similar to peanut (Arachis hypogaea) lectin at the level of the monomer, and thus serves as an example of the highly conserved monomeric structure of legume lectins. The unusual binding site of the carbohydrate (distal to the metal co-factors) is potentially influenced by the novel tetrameric arrangement of the monomers. This illustrates the importance of total structural characterization prior to assignment of definitive carbohydrate binding sites. Like other fucose-binding lectins, such as Ulex europaeus lectin II (doi:10.2210/pdb1QOO/pdb), LTA complexes with $N$-acetyl-glucosamine, as pictured. Structures were downloaded from the protein data bank (PDB) (http://www.rcsb.org/) through Chimera (Pettersen et al. 2004), oriented, and ray traced for visualization

various stresses (Van Damme et al. 2004; He et al. 2004). Although recent evidence shows that a new class of lectins is translated on free ribosomes destined for the cytoplasm or the nucleus (Fouquaert et al. 2008), their function in the plant has not yet been resolved. Even less is known about the sugar-binding functions of the lectin receptor kinases (LecRKs) or whether there are plant transmembrane lectins involved in endocytosis, as there are for phagocytosis in animal cells. The presence of transmembrane lectins encoded by all well-characterized plant genomes hints at more generalized functions such as plant disease resistance or self-incompatibility, with the lectin component of the LecRKs potentially interacting directly with the cell wall (Gouget et al. 2006).

In spite of the extensive knowledge about the molecular biology and structure of lectins, their physiological role with respect to the plant is still not well understood. This is a broad topic, so in this review, we focus our discussion mostly to events that occur outside the plant cell, concentrating on recognition of self or non-self by lectins, especially by the legume lectins.

Lectins are involved in two types of interactions with microbes, i.e. symbiosis and defense, which differ substantially in their downstream host responses. An analogy can be made to the Roman deity Janus - god of gates and doors and beginnings and endings - who is depicted as having two heads that face in opposite directions. Like Janus, 
lectins are dualistic, functioning in defense in one case and in recognition of a compatible symbiont in the other (Sharon and Lis 2004). Because of the difficulty in conceptualizing how lectins are able to recognize both friend and foe, a universal hypothesis about the mechanism of lectin function in modulating these seemingly opposite roles has not been developed. We will propose such a model, first discussing the evidence, and then address how model legumes may help us understand some of the endogenous roles of lectins in the plant.

\section{Lectin localization in the plant}

\section{Seed lectins}

Lectins were first characterized as sugar-binding proteins from seeds where they function as storage proteins, and additionally may display anti-pathogenesis and anti-predation functions against microbes, insects, and herbivores (Brewin and Kardailsky 1997). Lectin levels rapidly decrease in seed cotyledon tissue shortly after germination with the same kinetics as other seed storage proteins because they are catabolized for energy or for amino acid building blocks (Pusztai 1991).

Most plant lectins, and all known secreted ones, are synthesized on membrane-bound polyribosomes as propeptides with a signal sequence. Before introduction into the lumen of the rough endoplasmic reticulum and sequestration within the Golgi apparatus, several processing steps occur, including cleavage of the signal peptide and addition of oligosaccharides to the polypeptide chain at specific asparagine residues. Glycosylation is thought to mediate the targeting of the lectins to their final destination (Pusztai 1991). In addition, given the presence of the calnexins and calreticulins in plants, previously described as being involved in protein folding checkpoint processes, and the extensive hydrophobic cores of lectin proteins, glycosylation events may also facilitate proper lectin folding prior to export (Banerjee et al. 2007). These steps are followed by accumulation in protein storage bodies or signal sequence-mediated protein localization (Chrispeels 1984; Lord 1985; Vitale and Bollini 1995). Lectins stored within vacuoles or protein bodies are likely to function in defense because when an invading microbe or insect disrupts the plant's cellular contents, the stored lectin, which may agglutinate or sicken the pathogen or predator, is released (Chrispeels and Raikhel 1991).

Legume lectins are also immunolocalized to roots and root hair tips (Díaz et al. 1995; van Rhijn et al. 1998) and secreted into the extracellular environment (Wen et al. 2007), most likely as a consequence of the default secretion pathway that is mediated by the fusion of Golgi vesicles to the plasma membrane. However, it has yet to be elucidated if the secreted plant lectins are proteolytically cleaved from the membrane or are bound to other proteins or to the membrane itself. Because galectins are released from outer membranes by enzymatic digestion of surface carbohydrates (Garner and Baum 2008), it is possible that soluble plant lectins are also linked to a region near the plasma membrane through interactions with surface glycoproteins. Secretion of plant lectins into the medium may enable a role in defense or symbiosis via bacterial or fungal binding and subsequent agglutination.

Cereal lectins such as WGA are also synthesized as propeptides and secreted (Vitale and Bollini 1995). Additionally, WGA and its homologs have been immunolocalized to the coleoptiles of embryos and to the epidermal cells of aerial and subterranean organs of wheat, rice, and barley, serving in these locations as potential mediators of plant defense (Mishkind et al. 1982, 1983).

\section{Vegetative lectins}

Some lectins such as PSL, SBL, and WGA are not only expressed in seeds, but also at low levels in roots, and in the case of lectins from nodulating legumes, in nodules as well. The vegetative or bud (BLEC) lectins share sequence similarity with the seed lectins but are predominantly found in roots, nodules, and aerial tissues. For example, the $P$. sativum BLEC4 protein displays 37 and 52\% sequence identity with PSL and L. tetragonolobus seed lectin, respectively (Mandaci and Dobres 1993). In addition, the DB58 protein from Dolichos biflorus displays sequence similarity to the $D$. biflorus seed lectin, but is localized to stem and leaf tissues and not found in seeds (Schnell and Etzler 1988). As an example of a lectin with a limited spatial expression pattern, PsNlecl encodes a glycoprotein that was purified from symbiosomes of pea nodules (Kardailsky et al. 1996). Its sequence is similar to PsBlecl but less similar to genes encoding legume seed lectins. PsNlecl is expressed in nodules, even in those of a pea mutant that does not fix nitrogen $\left(\mathrm{Fix}^{-}\right)$. Northern blot analysis failed to detect the corresponding mRNA in buds, leaves, stems, roots, and seeds (Kardailsky et al. 1996).

The bark lectins are thought to exist primarily for defense against predators. Bark lectins from the legume Robinia pseudoacacia are abundant and have been extensively characterized. The most prominent inner bark proteins are a mixture of five isolectins, which were identified as tetrameters composed of two distinct subunits. These lectins also demonstrate sequence similarity to the R. pseudoacacia seed lectins (Van Damme et al. 1995a, b). Likewise, Sophora japonica bark lectins demonstrate sequence similarity to legume seed lectins (Herman et al. 1988), and like legume seed lectins, they accumulate in leaf and bark vacuoles, mimicking the protein bodies of seeds. 
The advent of genomics and the application of mRNA expression profiling have allowed the discovery of large numbers of genes with lectin or lectin-like domains in legumes and in plants in general, shedding new light on the lesser-studied endogenous roles of lectins in plants. In contrast with earlier findings showing that lectins are expressed primarily in seeds, microarray data demonstrate that putative lectin genes are expressed in a multitude of tissues showing a mixture of unique and overlapping expression patterns (Schmid et al. 2005; Sato et al. 2008; Benedito et al. 2008). Basal lectin expression levels vary by organ structure, and can change in response to microorganisms or to other environmental stimuli. For example, examination of the expression pattern of the Medicago truncatula Lectin 1 (MtLec1) protein, the homolog of PSL and Medicago sativa Lectin 1 (MsLec1), shows that there are high expression levels in the root just prior to inoculation with rhizobia with ca. 1/6 as much expression as in the seed (Benedito et al. 2008). MtCalreticulin, which is involved in protein folding checkpoints, varies by as much as 8 -fold in its expression levels across tissue types and in response to microorganism challenge (Benedito et al. 2008). It appears likely, on the basis of these recent expression studies, that the role of lectin in plants is more extensive than solely serving as a storage protein in the seed.

\section{Lectins in defense and symbiosis}

\section{Defense}

In animal cells, lectins play a role in defense as part of an innate immunity response. In the lectin-complement pathway, lectins recognize a diversity of pathogens, most likely by interacting with a subset of pathogen-produced molecules, known as pathogen-associated molecular patterns (PAMPs) or microbe-associated molecular patterns (MAMPs), i.e. lipopolysaccharides, chitin oligomers, glycans, and other carbohydrate-containing molecules as well as peptides and proteins. Recognition of the ligands by the lectin triggers the activation of an associated serine protease, which results in the opsonization (alteration of susceptibility to phagocytosis) of the pathogen (Fujita et al. 2004; Robinson et al. 2006). Galectins, soluble animal lectins, cross-link surface glycoproteins to form lipid rafts in T-cells that permit their proper response to pathogen challenge (Garner and Baum 2008). Although galectin is not present in plants, we are unaware of any evidence showing that transmembrane LecRKs are present in animals. Hence, the LecRKs in plants may represent an alternate means to achieve a similar biological response, i.e. agglutinating receptor molecules to enhance the response to external stimuli and to amplify the signal from the receptor. This proposal is consistent with the identification of both soluble lectins and LecRKs in M. truncatula lipid rafts (Lefebvre et al. 2007).

Several reviews have described the prevailing view of how lectins are involved in plant defense (Chrispeels and Raikhel 1991; Peumans and Van Damme 1995). For example, soybean cultivars that are resistant to root rot caused by Phytophthora megasperma var. sojae have twofold more SBL than susceptible cultivars (Gibson et al. 1982). SBL released from imbibing seeds of resistant cultivars binds to P. megasperma var. sojae and inhibits its growth. PHA activity is increased at sites of bean root wounding (Hamblin and Kent 1973), suggesting that lectins may facilitate defense at wounds, which are especially susceptible to infection by pathogens. Similarly, chitin-binding lectins attach to fungal pathogens and may act synergistically with chitinases to inhibit fungal growth (Mirelman et al. 1975; Broekaert et al. 1989; Lerner and Raikhel 1992).

Lectins also function as feeding deterrents against insects. As a consequence, genes encoding Allium sativum (garlic) leaf and bulb lectin (Sadeghi et al. 2003), Galanthus nivalis (snowdrop) agglutinin (Nagadhara et al. 2004), and pea lectin (Melander et al. 2003) have been introduced into tobacco, wheat, and rice to reduce predation by phloem-feeding insects such as aphids. The transgenes generally reduce but do not completely eliminate predation by these pests. As demonstrated by purified and transgenic SNA-I from elderberry and other plants, the toxic effects of lectins, which bring about a loss of insect fecundity, are generally mediated by the sugar-binding domain of lectin and occur at physiological levels (Shahidi-Noghabi et al. 2008).

However, mechanisms other then toxicity, whereby lectins confer resistance to plant bacterial and fungal pathogens, remain poorly defined. Lectin's ability to agglutinate pathogens at a distance from the plant, especially from roots, may be considered a type of plant innate immunity that functions as the plant's first line of defense (Hawes et al. 1998).

\section{Symbiosis}

Before the discovery that the primary determinant of hostRhizobium specificity depended on the interaction between Rhizobium-derived lipo-chitin oligosaccharides (Nod factors) and LysM receptor kinases in the legume host (Oldroyd and Downie 2008), legume seed lectins were proposed as mediators of specificity between the two symbiotic partners (Hamblin and Kent 1973; Bohlool and Schmidt 1974; Dazzo and Hubbell 1975). Several legume seed lectins play a role in rhizobial binding to the plant roots or in ex planta carbohydrate-based signal detection (Díaz et al. 1989; Van Eijsden et al. 1995; Kijne et al. 1997; 
van Rhijn et al. 1998, 2001; Hirsch 1999). These lectins are most abundant in seeds but are present at lower levels in other tissues (Pusztai 1991; Benedito et al. 2008). Legume seed lectins bind to carbohydrate moieties on the bacterial surface and either agglutinate the bacteria at a distance away from the root or assist in the initial attachment phase of bacteria, frequently rhizobia, to root epidermal cells. This curious dichotomy in location and function of the lectin can be resolved if lectins are both associated with the plasma membrane and are being secreted from the surface of the root into the secretome. Presuming that the legume in question is growing under nitrogen stress and compatible rhizobia exist in the environment, successful bacterial attachment to root hairs will facilitate infection thread formation, which is required for effective root nodule development.

Gain-of-function experiments support a new version of the lectin hypothesis whereby lectins facilitate rather than direct the symbiosis. For example, when the PSL gene (pea is nodulated by Rhizobium leguminosarum bv. viciae) was introduced by Agrobacterium rhizogenes-mediated transformation into Trifolium repens (white clover, nodulated by R. leguminosarum bv. trifolii) (Díaz et al. 1989; Van Eijsden et al. 1995), R. leguminosarum bv. viciae-inoculated clover roots formed fully functioning nodules, albeit they were delayed and less efficient. This effect required a functional carbohydrate-binding domain of the lectin.

As the divergence between target legume and the host compatibility of the Rhizobium-derived Nod factor increases, the ability of cross-species plant lectin addition to broaden the range of nodulation-competent rhizobial species decreases. Nevertheless, Lotus corniculatus (normally nodulated by Mesorhizobium loti) transgenic for SBL, strongly bound Bradyrhizobium japonicum, the compatible soybean rhizobia, but only bacteria-free, ineffective nodules developed (van Rhijn et al. 1998). Similarly, when Medicago sativa (alfalfa, nodulated by Sinorhizobium meliloti) contained either the $P S L$ or $S B L$ transgene, the plants were not nodulated by wild-type $R$. leguminosarum bv. viciae, which is specific for pea, nor by $B$. japonicum, the soybean symbiont, unless the nod genes from S. meliloti were introduced into the inoculating strain. Nonetheless, even though nodules formed on the transgenic alfalfa roots in response to $R$. leguminosarum bv. viciae with the $S$. meliloti nod genes, the infection threads aborted. Similarly, $S$. meliloti nod gene addition to $B$. japonicum resulted in the formation of small bumps on the transgenic $S B L$-alfalfa roots, but no bona fide infection threads were observed (van Rhijn et al. 2001). Interestingly, roots of transgenic rice (a species that establishes symbiotic mycorrhizal associations, but is not nodulated by rhizobia) carrying an introduced legume lectin, PSL or Glycine max lectin apyrase (GS52), were colonized by rhizobia (R. leguminosarum, B. japonicum, and Rhizobium sp. NGR234) to a greater extent than the control roots (Sreevidya et al. 2005). Moreover, the rhizobia preferentially attached to root hair tips, a location where legume lectins are typically localized. The authors hypothesized that recognition of lectin and enhanced attachment by the rhizobia led to structural modifications of the cell wall, similar to a model proposed by Kijne et al. (1997).

Lectins as putative Nod factor receptors

A LecRK DB46, also known as lectin nucleotide phosphohydrolase (LNP) because of its apyrase activity, was originally isolated from D. biflorus (Etzler et al. 1999), a legume that forms determinate nodules. This protein, which has no sequence similarity to previously described legume lectins, was proposed to serve as a receptor for Nod factor, a lipochitooligosaccharide that contains as part of its structure, an $N$-acetyl glucosamine oligomer. When Nod factor bound to DB46/LNP, the latter's apyrase activity increased, suggesting that this novel lectin transmitted the Nod factor signal throughout the plant. Furthermore, DB46/LNP is localized to root hair tips, expressed in root zones that participate in nodule development, and showed increased expression levels under nitrogen-limiting conditions (Etzler et al. 1999), all of which are consistent with a novel role in establishing nodulation. However, signal sequence prediction, hydrophobicity plots, and direct experimental evidence indicated that DB46/LNP is peripheral to the membrane (Kalsi and Etzler 2000). As such, it seems likely that DB46/LNP either interacts with a transmembrane-binding partner to propagate perception of the Nod factor signal, or the localized product of its enzymatic activity transmits the signal.

Antisera to DB46/LNP, or to the soybean homolog (GS52), inhibited nodulation in these species, respectively. This finding suggests that signaling in which DB46/LNP and orthologs participates may be conserved among legumes (Day et al. 2000; Roberts et al. 1999). Four putative apyrase genes were isolated from $M$. truncatula, which forms indeterminate nodules (Cohn et al. 2001). Two of these, Mtapyl and Mtapy4, are induced $<3 \mathrm{~h}$ post-inoculation, suggesting that they could be classified as Early Nodulin $(E N O D)$ genes. Moreover, nodulation-defective mutants of $M$. truncatula did not express these two apyrase genes, consistent with the proposal that they play an important role in the early stages of nodule formation. However, other reports indicate that the Mtapy genes are not involved in symbiosis but rather are related to stress responses (Navarro-Gochicoa et al. 2003).

Gain-of-function experiments whereby the soybean GS52 apyrase gene was introduced into $L$. japonicus yielded enhanced nodulation and infection thread development following inoculation with Mesorhizobium loti (McAlvin and Stacey 2005). However, loss-of-function 
experiments have not been reported, making it unclear what role lectin-apyrases play in the Rhizobium-legume symbiosis. Bona fide antisense GS52 L. japonicus lines did not regenerate, indicating that when the native $L j L N P$ was knocked down, it potentially has functions beyond nodulation. Plants that survived exhibited a wild-type nodulation phenotype suggesting that the transgene had been lost (McAlvin and Stacey 2005). It is certainly possible that the effects seen by the GS52 and DbLNP are related to alterations of local ATP concentration, which might lead to localized hormonal changes, initiate full signal transduction, or perhaps "prime the pumps" of other more specific receptor kinase molecules (Sreevidya et al. 2005). In any case, the precise signaling pathway of these LNPs remains unclear, as well as whether they are essential for nodulation.

\section{Lectins and mycorrhizal symbioses}

Of interest is the fact that several genes critical to the Rhizobium-legume symbiosis are also required for the arbuscular-mycorrhizal (AM) phosphate-acquiring mutualism. Some of these conserved genes, MsNORK/MtDMI2/ LjSYMRK/PSSYM19, MtDMII/CASTOR-POLLUX, and $C C a M K$, when mutated in legumes, yield both $\mathrm{Nod}^{-}$and $\mathrm{Myc}^{-}$phenotypes (Oldroyd and Downie 2008). Other genes such as several ENOD genes, which are induced in both symbioses (van Rhijn et al. 1997; Albrecht et al. 1998), may reflect the similar hormonal and physiological conditions of these two beneficial plant-microbe interactions.

Annotation studies of genes induced in an AM (Glomusintraradices- $M$. truncatula) association uncovered a novel lectin family that is specifically expressed in mycorrhizal roots (Frenzel et al. 2005). Based on this and earlier work (Wulf et al. 2003), at least seven different AM lectin-specific gene sequences were identified. Several of these appear to be secreted lectins, based on lectin-GFP fusion analyses, and inducible by mycorrhizal association (Frenzel et al. 2006). Using promoter fusions, two of the lectin family members were found to be expressed in plant cells containing arbuscules, and were proposed to serve as vegetative storage proteins (Frenzel et al. 2005). However, recent analysis of their expression patterns in mycorrhizaefree tissue indicates that these lectins are expressed at very low levels, unlike the putative storage protein lectins. Taking into account that it is known that plant-secreted proteins may directly integrate into cell walls (Meyer et al. 2008), it is possible that these secreted lectins are involved in the symbiotic interaction between the fungus and the plant (Benedito et al. 2008). It is important to note that this potential role may be restricted to only some lectins because a two-dimensional gel-based proteomic study of membrane-associated proteins found that the intensity of spots corresponding to an unidentified lectin actually decreased in response to $G$. intraradices colonization of M. truncatula (Valot et al. 2005).

Lectins appear to be involved in the ectomycorrhizal symbioses as well, where they are proposed to function in recognition between the fungus, the source of the lectin, and its host (Giollant et al. 1993). It is worth noting that in a symbiosis between two species, there is a complex interplay of various factors, several of which are likely to be involved in the direct modulation of the interface between the two partners. The localization of lectins to this interface and their role in cross-linking glycosylated proteins increases the likelihood that lectins are involved in that reshaping process.

\section{LecRKs}

Putative receptor kinases with lectin domains were first identified in Arabidopsis (Hervé et al. 1996) with at least 46 members (Barre et al. 2002); nine have been identified in the legume M. truncatula (Navarro-Gochicoa et al. 2003). However, a search of the most recent $M$. truncatula genome sequence database reveals that 86 LecRKs are likely to be present, but the exact number is not known.

This class of proteins has an N-terminal signal peptide, an extracellular lectin-like domain that contains extensive sequence similarity to the soluble legume lectins described earlier, a transmembrane-spanning region, and a cytosolic domain predicted to be a Ser/Thr kinase. Furthermore, EGFP-LecRK fusion proteins localize to membranes of transgenic tobacco cells (Sasabe et al. 2007), and GFPLecRK fusions of MtLecRK7;2 and MtLecRK1;1 are localized to M. truncatula root membranes (Navarro-Gochicoa et al. 2003). Although many of these proteins fail to exhibit detectable monosaccharide-binding activity, they may bind hormone ligands such as cytokinins or auxins or more complex oligosaccharides (Barre et al. 2002). Most LecRKs are predicted to possess the typical hydrophobic face associated with lectin dimerization. It is unclear whether these lectins form homo- or heterodimers with the soluble lectins, other LecRKs, or other proteins. It is also possible that the lectin domain is secondary to their primary function as a receptor kinase because most, but not all, L-type LecRKs lack other identifiable extracellular domains beyond the lectins. Because some LecRKs have been shown to interact with their ligand on the cytosolic side of the membrane (Kanzaki et al. 2008) and because receptor-mediated endocytosis is known to occur in plants (Leborgne-Castel et al. 2008), it is possible that the purpose of the extracellular lectin in the LecRK is to anchor the lectin to a particular area 
of the plasma membrane, via the lectin domain's association with surface protein glycosylation, perhaps in lipid rafts (Lefebvre et al. 2007). This could serve to cluster a number of receptors together so that signaling of the active LecRK, by clatherin-mediated endocytosis or otherwise, would be amplified.

The mRNAs encoding four LecRKs that are highly expressed in $M$. truncatula roots are up-regulated by nitrogen starvation and one of them, MtLecRK1;1, could potentially interact with Nod factor based on molecular modeling studies (Navarro-Gochicoa et al. 2003). Nevertheless, the protein could not be detected in non-transformed roots. Under conditions of nitrogen stress, MtLecRK1;1, 7.2, and 7.3 fusion proteins are expressed primarily in roots and early stage nodules, and are thus likely to be involved in the early nodulation processes. Their overlapping expression patterns, however, will present challenges of redundancy in deciphering their specific activities during nodule initiation (Benedito et al. 2008).

Although roots overexpressing MtLecRK1;1 established more nodules upon $S$. meliloti inoculation, no increase in Nod factor binding was observed, suggesting that Nod factor is not a ligand for this LecRK. However, the assay used to detect this interaction was designed for high affinity interactions and not to detect potential Nod factor $\mathrm{K}_{\mathrm{D}}$ 's in the high $\mu \mathrm{M}$ to low $\mathrm{mM}$ range (Navarro-Gochicoa et al. 2003).

Interestingly, an Arabidopsis LecRK, At5g60300 recognizes peptides containing RGD (asparagine-glycine-aspartic acid), a tripeptide motif characteristic of proteins involved in cell adhesion between the plasma membrane and the cell wall (Gouget et al. 2006). The possibility exists that LecRK proteins are important for protein-protein interactions, including interacting with typical legume lectins via hydrogen bonds and Van der Waals forces, and furthermore, that they play an important structural and signaling role at the plant cell surface (Gouget et al. 2006). Of note is that the RGD interaction domains, which were found by phage display, are not in the sugar-binding pocket but rather at peripheral locations on the LecRK molecule. In addition to At5g60300, several other lectin-like RLKs were shown to possess this RGD binding motif and could potentially be players of physiological relevance in Phytophthora pathogenesis.

There are few reports of the effects of LecRK knockouts in plant development or symbiosis. An exception is a recent study (Wan et al. 2008) describing male sterility in an AtLecRK knockout. This mutant is defective in early to middle stages of pollen development and by sequence similarity, the mutation appears to be in a homolog of $M t$ LecRK7;1. This gene is expressed in M. truncatula flower and pod, although at relatively low levels (Benedito et al. 2008). Although it was proposed that the lectin domain in
Fig. 2 Neighbor-joining tree of selected lectin protein sequence alignment. Signal sequences have been removed. At Arabidopsis thaliana, Gm Glycine max, Lj Lotus japonicus, Ma Melilotus alba, Ms Medicago sativa, Mt Medicago truncatula, Nt Nicotiana tabacum, Ps Pisum sativum, Rp Robinia pseudoacacia, Vv Vitis vinifera. SignalP (Bendtsen et al. 2004) was used to predict the signal peptides, ClustalX (Larkin et al. 2007) to generate the alignments, and ATV (Zmasek and Eddy 2001) to visualize the data. Bootstrap values on the branches represent a repeat of 1,000 with a random start number of 111 . Genbank IDs follow species/protein names. Names beginning with "chr" are contig identifiers in the Lotus japonicus genomic database (http://www.kazusa.or.jp/lotus/). See text for additional details

this $A t$ LecRK may be involved in detecting pollen cell wall degradation products as the pollen develops, so far no direct biochemical evidence demonstrates a functional sugar-binding partner for the lectin domain.

\section{Use of model legumes to study lectins and lectin-like proteins}

Few investigations have analyzed the endogenous role of the lectins in symbiosis and defense using lectin loss-offunction approaches. Several legume lectin (le1) mutants have been described, including the soybean lel ("Sooty") mutant, but no obvious nodulation phenotype was observed (Pull et al. 1978). Several pea mutants with variable lectin levels have also been described (Boyd et al. 1961), but to our knowledge, no studies on either symbiosis or defense responses have been reported with these plant lines.

A loss-of-function approach using whole plant RNA antisense-mediated knockdown of the $M$. sativa lectin 1 gene $(M s L E C l)$ resulted in sickly and deformed plants whereas MsLEC2 knockdown had a less deleterious effect on plant health (Brill et al. 2001). The pleiotropic effects of $M S L E C 1$ knockdown were either due to off-target activity of the antisense constructs or to MsLECl's involvement in multiple, essential biochemical pathways. Nevertheless, the reduced expression of $M S L E C l$ significantly reduced the number of nitrogen-fixing nodules because of premature nodule senescence (Brill et al. 2004). Southern blot analysis indicated that three copies of a seed-type lectin gene exist in the alfalfa genome (Brill 1997), one of which, MsLEC3, is a pseudogene (W.M. Karlowski and A.M. Hirsch, unpublished results). M. truncatula, a model plant for studying legumes that establish indeterminate nodules, also has three homologous seed lectin genes; MtLEC2 is a pseudogene (Bauchrowitz et al. 1992). The MtLecl gene appears to be the highest expressed of the three, with expression primarily in the seed, ca. $1 / 3$ as much in the stem and ca. $1 / 6$ as much in the root. MtLecl is the homolog for the M. sativa MsLecl gene. MtLec3 is expressed, but to a minor extent, and MtLec2's expression is undetectable. 


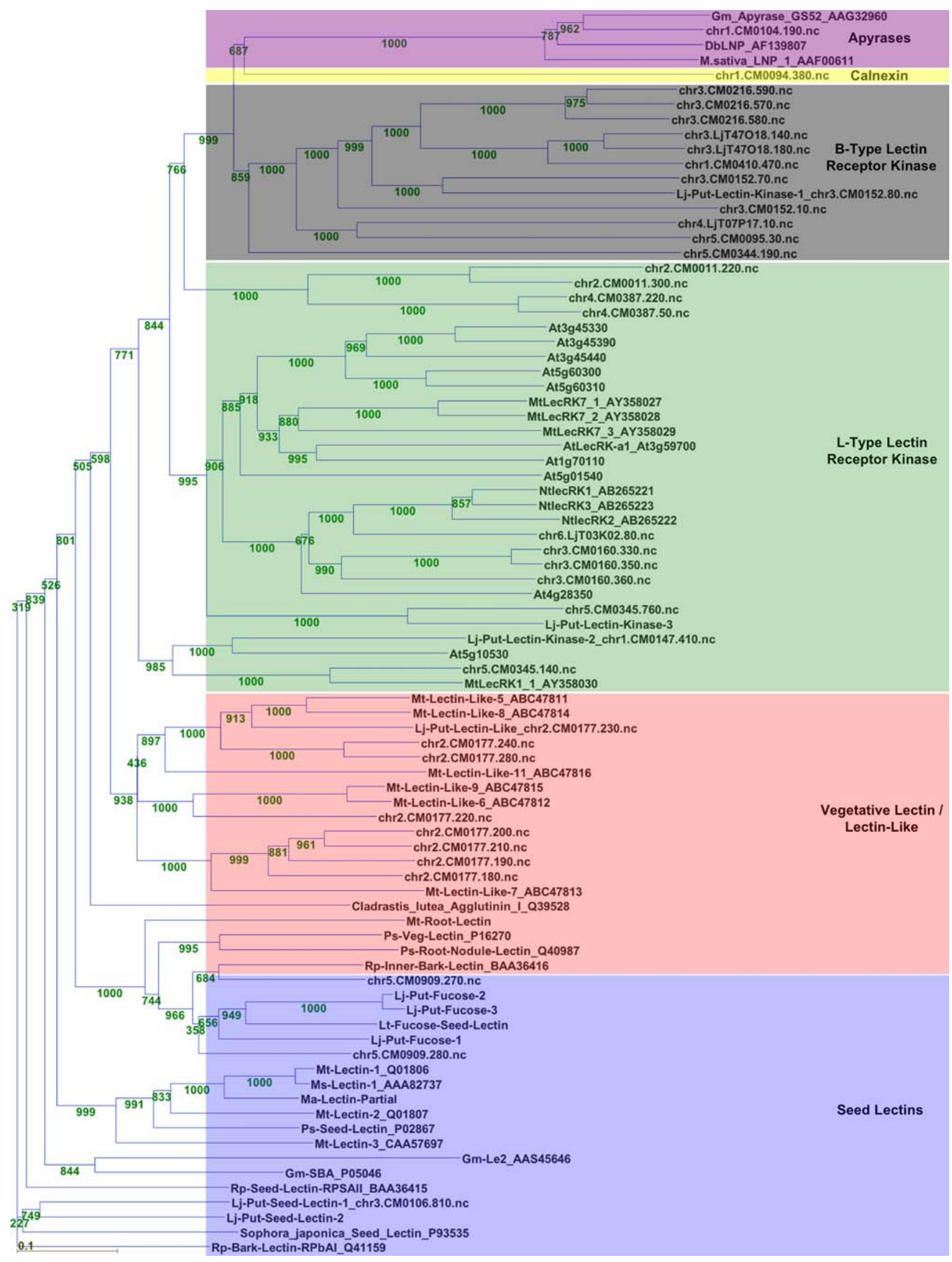




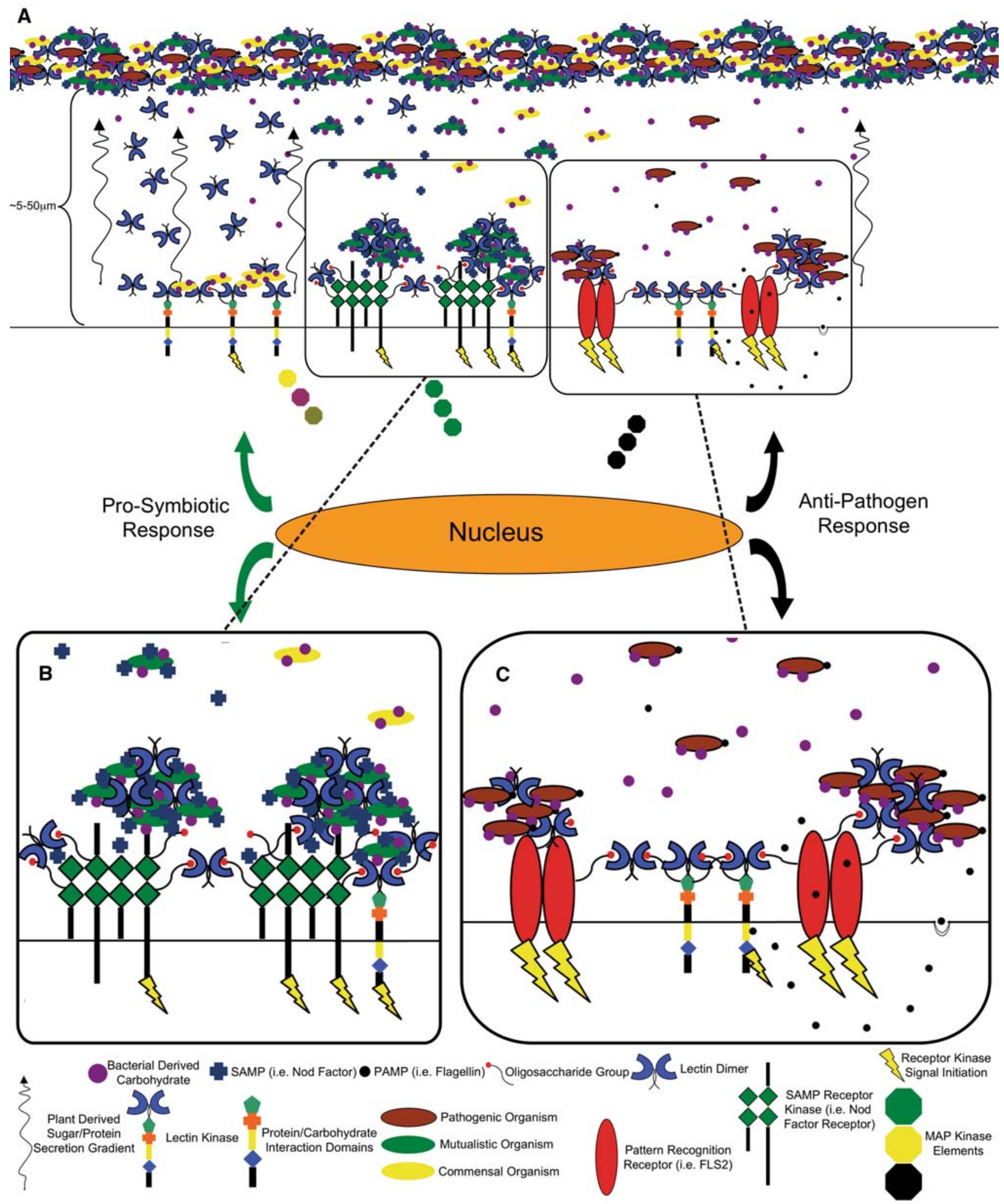

A Southern blot analysis of Melilotus alba (white sweetclover, which also develops indeterminate nodules following inoculation with $S$. meliloti), when probed with
MsLEC1 from M. sativa demonstrated that only one copy of a seed lectin gene could be detected (Brill, 1997). MaLEC from M. alba is similar to MsLEC1 (84\% identity/ 
4 Fig. 3 a Hypothetical model to illustrate the perception of pathogenic, symbiotic, or commensal bacteria. A sugar/protein gradient is exuded from the root to permit the growth of potentially mutualistic organisms in the rhizosphere. Soluble lectin agglutinates most bacteria (illustrated) and fungus (not shown) along the root periphery. Those bacteria that elude this first line of defense, either through evasion or persistence, as well as isolated PAMPs or symbiont-associated molecular patterns (SAMPs); Hirsch 2004) bind to protein recognition receptors (PRRs) or lectins at the root surface. This binding activates kinase domains, triggering a cascade of MAP kinases leading to antipathogen responses or pro-symbiotic responses. Lectin kinases and soluble lectins agglutinate surface transmembrane proteins, helping to stabilize lipid rafts for enhanced downstream protein signaling. B-lectin kinases are diagrammed here with typical twin Pfam domains [usually a Pan/Apple (cd01098) and a S-locus (pfam00954)] proximal to the membrane from the lectin domain. L-lectin receptor kinases only contain a Pfam L-lectin domain in the extracellular space (not shown). Commensal bacteria either do not elicit a response, or lack symbiotic and pathogenic responses. b Enlargement of the mutualistic interaction with SAMP receptors (such as Nod factor receptor) responding to locally increased Nod factor concentrations due to localized agglutination of the compatible bacteria. c Enlargement of the pathogenic interaction showing soluble lectins and LecRKs agglutinating PAMP receptors. LecRK responses to pathogen effectors are known to occur on the cytoplasmic side of the membrane, as indicated. See text for additional details

90\% similarity) and MtLEC1 (82\% identity/88\% similarity), with lesser sequence homology to $P S L$ as well as cross-reactivity of the protein to antibodies raised against either PSL or Lens culinaris lectin (van Rhijn et al. 2001). Hairy roots of $M$. alba with RNAi targeting MaLEC expression showed fewer defects than $M$. sativa containing antisense-MsLECl sequences (P.L. De Hoff and A.M. Hirsch, in preparation). However, a change in root cap structure was observed, consistent with findings illustrating that lectin is in the root secretome (Díaz et al. 1995; van Rhijn et al. 2001; Wen et al. 2007) (P.L. De Hoff and A.M. Hirsch, in preparation). Curiously, hairy root cultures showing MaLEC gene knockdown exhibit much higher susceptibility to Fusarium oxysporum root tip colonization, implicating this lectin in root defense. It is not yet clear if the MaLEC protein directly interacts with the pathogen, or if this is a secondary effect related to looser attachment of the root tip border cells (P.L. De Hoff and A.M. Hirsch, in preparation).

Lotus japonicus is a model legume for the study of determinate nodules. Unlike G. max, L. japonicus has a much less complex genome that does not appear to have undergone massive gene duplication, and is readily and reproducibly transformable. To date, no studies have reported endogenous lectin function in this species and in the genus, only one lectin structure, L. tetragonolobus lectin, has been determined (Fig. 1b), yet its complement of lectin genes exhibits composite homology to those of soybean and Medicago. Thus, L. japonicus represents a potential new model for investigating legume lectins. The genome structure of L. japonicus accession Miyakojima MG-20 has been recently described; $67 \%$ of the genome, covering $91.3 \%$ of the gene space has been analyzed and various microarrays are available (Sato et al. 2008). The combination of genome sequence and cDNA arrays provides an exciting opportunity to examine the type and number of lectins present in L. japonicus. An in silico analysis of a more completely annotated subset of the L. japonicus genome yields dozens of genes with lectin and lectin-like domains. Some are predicted to be soluble lectins whereas others have domains that are potential transmembrane kinases (Fig. 2). Some lectins cluster with genes encoding the M. truncatula lectin-like proteins involved in the mycorrhizal symbiosis whereas others are potentially lectin-kinases whose functions are not yet elucidated. Other genes include vegetative lectins or seed lectins related to PSL and SBL. These genes and the putative lectin kinases offer targets for functional analysis to determine the role(s) of lectins in plants.

As seen in Fig. 2, the L. japonicus lectin sequences span the groups of lectins, illustrating the breadth of this model legume's repertoire of lectins. Of particular note is that the LecRKs listed here lack Pfam (collection of protein families that are represented by multiple sequence alignments and hidden Markov models; http://pfam.sanger.ac.uk/) (Finn et al. 2008) identifiable extracellular protein domains beyond the LegB domain (pf00139), perhaps due to functional requirements that the kinase domains be located in lipid rafts. Conversely, the B-lectin kinases generally contain an S-locus (pfam00954) and Pan/Apple-like domains (cd01098), both involved in self-incompatibility/fertilization pathways, suggesting a potential role for these proteins. Curiously, a parsimonious reading of the tree strongly suggests that lectin kinases evolved from the addition of a kinase domain to a primitive soluble lectin as opposed to the loss of a kinase domain from a LecRK.

\section{Epilogue: a model for tying lectins to symbiosis and defense}

Innate immunity is mediated via the interaction between pattern recognition receptors (PRRs) and PAMPs (Janeway 1989). When this recognition occurs and mitogen activated protein kinase (MAPK)-based signal transduction pathways are triggered, basal resistance or PAMP-mediated immunity (PMI) is elicited in plants as well as in animals (Jones and Dangl 2006; Kanzaki et al. 2008; Martínez Zamora et al. 2008; Zipfel 2008). In the classic example for plants, FLS2, the Arabidopsis PRR, recognizes a 22-amino acid PAMP derived from the flagellin protein of pathogenic bacteria and triggers a host defense response (Felix et al. 1999). How do lectins fit into this scenario? We propose a new model that binds various phenomena together, and is consistent with the literature discussed in this review. 
The extracellular milieu is a complex environment in which pathogenic, symbiotic, and commensal organisms aggregate in a rhizosphere where not only proteins but also sugars released by these organisms as well as by the plant root, accumulate. The microbes in the vicinity of the root are attracted by chemotaxis to root-secreted nutrients and move towards them. However, the microbes could become immobilized by a first line of defense (roughly estimated to be $5-50 \mu \mathrm{m}$ from the root surface), where multimeric plant lectins and probably other molecules in the rhizosphere may agglutinate them (Fig. 3). Nevertheless, this barrier is not impenetrable, and a fraction of the microbes may migrate to the root surface, permitting the controlled sampling of the local environment by the root. At the root surface, the organisms that evade the secreted lectins are likely to interact with lectins again, via interactions with their surface carbohydrates, and agglutinate near pathogen and/or symbiotic recognition receptors. These lectin and receptor proteins are potentially associated together in lipid rafts at the cell surface, which permits the amplification of a signal resulting from their perception by the root. The lectin domains in the LecRKs are likely to agglutinate these molecules via the carbohydrates of other glycosylated surface proteins. Degradation of the cell wall might also be detected by ancillary domains on the lectin structure and transmitted to the plant for a response (not shown in Fig. 3 for the purpose of brevity). In pathogenic and mutualistic interactions, the cell wall is degraded (Robledo et al. 2008), and both scenarios result in the upregulation of genes involved in plant defense. In pathogenesis, the defensive response is maintained, but in mutualistic symbiosis, the response is dampened (Gibson et al. 2008). In the Rhizobium mutualistic symbiosis, Nod factor may play a role in either down-regulating the defensive response or inhibiting its transduction, through the direct or indirect interaction with an RK or LecRK.

The model presented in Fig. 3 also illustrates a possible reconciliation between the apparent dual roles of plant lectins in symbiosis and defense. In Fig. 3a, when symbiotic organisms such as Rhizobium attach to legume roots, microbes (green-colored bacteria, left side) colonize the root surface. Increased concentration of rhizobial cells facilitates local recognition of Nod factor from a compatible Rhizobium by putative Nod-factor receptors (Oldroyd and Downie 2008), possibly in a lipid raft. When pathogens (brown-colored bacteria, right side) are detected by FLS2 or by lectins, immediate and local responses (i.e. an oxidative burst) and systemic responses (via MAPK cascades) are triggered, and the further ingress of the pathogen is curtailed. The effector proteins from the bacteria may also be taken up intracellularly and detected internally by an RK. In the case of commensal bacteria (yellow or light-colored bacteria), neither a pathogenic nor symbiotic response is activated. The proposed interactions between mutualistic and pathogenic organisms are shown in greater detail in Fig. 3b, c, respectively. The plant bears the cost of largescale nutrient secretion for the potential to associate with symbiotic bacteria, but at the same time, must risk pathogenesis. Plant lectins could participate in balancing this transaction at the interface between pathogenic and mutualistic interactions. Understanding this duality of function is limited not only by our lack of information about the functions of all the players but also because many pieces of the puzzle remain unidentified. This is likely to change as the data provided by various model legume systems as well as the genomes, transcriptomes, and expression data related to them are becoming available.

Acknowledgments This paper was written in partial fulfillment of the Ph.D. thesis of P.L.D. to the Molecular Biology Institute (UCLA). The research was supported by UC-BIOSTAR grant S98-86, the Shanbrom Foundation, and the UCLA Council on Research (A.M.H) and by a NIH Genetics Training grant (P.L.D). We thank Martha C. Hawes for insights into border cells as the first line of the root's defense. These discussions helped crystallize our ideas regarding the duality of lectin function. Gratitude is also extended to Stefan J. Kirchanski for his helpful comments on the manuscript.

Open Access This article is distributed under the terms of the Creative Commons Attribution Noncommercial License which permits any noncommercial use, distribution, and reproduction in any medium, provided the original author(s) and source are credited.

\section{References}

Albrecht C, Geurts R, Lapeyrie F, Bisseling T (1998) Endo-mycorrhizae and rhizobial Nod factors both require SYM8 to induce the expression of the early nodulin genes PsENOD5 and PsENOD12A. Plant J 15:605-614

Arason GJ (1996) Lectins as molecules in vertebrates and invertebrates. Fish Shellfish Immunol 6:277-289

Banerjee S, Vishwanath P, Cui J, Kelleher DJ, Gilmore R, Robbins PW, Samuelson J (2007) The evolution of $N$-glycan-dependent endoplasmic reticulum quality control factors for glycoprotein folding and degradation. Proc Natl Acad Sci USA 104:1167611681

Barondes SH (1988) Bifunctional properties of lectins: lectins redefined. Trends Biochem Sci 13:480-482

Barre A, Hervé C, Lescure B, Rougé P (2002) Lectin receptor kinases in plants. Crit Rev Plant Biol 21:379-399

Bauchrowitz MA, Barker DG, Nadaud I, Rougé P, Lescure B (1992) Lectin genes from the legume Medicago truncatula. Plant Mol Biol 19:1011-1017

Bendtsen JD, Nielsen H, von Heijne G, Brunak S (2004) Improved prediction of signal peptides: SignalP 3.0. J Mol Biol 340:783-795

Benedito VA, Torres-Jerez I, Murray JD, Andriankaja A, Allen S, Kakar K, Wandrey M, Verdier J, Zuber H, Ott T, Moreau S, Niebel A, Frickey T, Weiller G, He J, Dai X, Zhao PX, Tang Y, Udvardi MK (2008) A gene expression atlas of the model legume Medicago truncatula. Plant J 55:504-513

Bogoeva VP, Radeva MA, Atanasova LY, Stoitsova SR, Boteva RN (2004) Fluorescence analysis of hormone binding activities of wheat germ agglutinin. Biochim Biophys Acta 1698:213-218 
Bohlool BB, Schmidt EL (1974) Lectins: A possible basis for specificity in the Rhizobium-legume symbiosis. Science 185:269-271

Boyd WC, Waszczenko-Zacharczenko S, Goldwasser SW (1961) Lists of plants tested for hemagglutinating activity. Transfusion 1:374382

Brewin NJ, Kardailsky IV (1997) Legume lectins and nodulation by Rhizobium. Trends Plant Sci 2:92-98

Brill LM (1997) Transgenic alfalfa plants expression antisense-lectin constructs display severe developmental, reproductive. defensive, and symbiotic abnormalities. Ph.D. Dissertation. University of California, Los Angeles

Brill LM, Evans CJ, Hirsch AM (2001) Expression of MsLEC1- and MsLEC2 antisense genes in alfalfa plant lines causes severe embryogenic, developmental and reproductive abnormalities. Plant J 25:453-461

Brill LM, Fujishige NA, Hackworth CA, Hirsch AM (2004) Expression of MsLEC1 transgenes in alfalfa plants causes symbiotic abnormalities. Mol Plant Microbe Interact 17:16-26

Broekaert WF, van Parijs J, Leyns F, Joos H, Peumans WJ (1989) A chitin-binding lectin from stinging nettle rhizomes with anti-fungal properties. Science 245:1100-1102

Chrispeels MJ (1984) Biosynthesis, processing, and transport of storage proteins and lectins in cotyledons of developing legume seeds. Philos Trans R Soc Lond Biol 304:309-322

Chrispeels MJ, Raikhel NV (1991) Lectins, lectin genes and their role in plant defense. Plant Cell 3:1-9

Cohn JR, Uhm T, Ramu S, Nam YW, Kim DJ, Penmetsa RV, Wood TC, Denny RL, Young ND, Cook DR, Stacey G (2001) Differential regulation of a family of apyrase genes from Medicago truncatula. Plant Physiol 125:2104-2119

Day RB, McAlvin CB, Loh JT, Denny RL, Wood TC, Young ND, Stacey G (2000) Differential expression of two soybean apyrases, one of which is an early nodulin. Mol Plant Microbe Interact 13:1053-1070

Dazzo FB, Hubbell DH (1975) Cross-reactive antigens and lectins as determinants of symbiotic specificity in the Rhizobium-clover association. Appl Environ Microbiol 48:1140-1150

Díaz CL, Melchers LS, Hooykaas PJJ, Lugtenberg EJJ, Kijne JW (1989) Root lectin as a determinant of host-plant specificity in the Rhizobium-legume symbiosis. Nature 338:579-581

Díaz CL, Logman TJJ, Stam HC, Kijne JW (1995) Sugar-binding activity of pea lectin expressed in white clover root hairs. Plant Physiol 109:1167-1177

Edelman GM, Cunningham BA, Reede GN, Becher JW, Waxdal MJ, Wang JL (1972) The covalent and three-dimensional structure of concanavalin A. Proc Natl Acad Sci USA 69:2580-2584

Etzler ME (1995) Plant lectins: molecular and biological aspects. Annu Rev Plant Physiol 36:209-234

Etzler ME, Kalsi G, Ewing NN, Roberts NG, Day RB, Murphy JB (1999) A Nod factor binding lectin with apyrase activity from legume roots. Proc Natl Acad Sci USA 96:5856-5861

Felix G, Duran JD, Voko S, Boller T (1999) Plants have a sensitive perception system for the most conserved domain of bacterial flagellin. Plant J 18:265-276

Finn RD, Tate J, Mistry J, Coggill PC, Sammut JS, Hotz HR, Ceric G, Forslund K, Eddy SR, Sonnhammer EL, Bateman A (2008) The Pfam protein families database. Nucleic Acids Res 36:D281D288

Fouquaert E, Peumans WJ, Smith DF, Proost P, Savvides SN, Van Damme EJ (2008) The "old" Euonymus europaeus agglutinin represents a novel family of ubiquitous plant proteins. Plant Physiol 147:1316-1324

Frenzel A, Manthey K, Perlick AM, Meyer F, Pühler A, Küster H, Krajinski F (2005) Combined transcriptome profiling reveals a novel family of arbuscular mycorrhizal-specific Medicago truncatula lectin genes. Mol Plant Microbe Interact 18:771-782
Frenzel A, Tiller N, Hause B, Kajinski F (2006) The conserved arbuscular mycorrhiza-specific transcription of the secretory lectin MtLec5 is mediated by a short upstream sequence containing specific protein binding sites. Planta 224:792-800

Fujita T, Matsushita M, Endo Y (2004) The lectin-complement pathway-its role in innate immunity and evolution. Immunol Rev 198:185-202

Garner OB, Baum LG (2008) Galectin-glycan lattices regulate cellsurface glycoprotein organization and signalling. Biochem Soc Trans 36:1472-1477

Gegg CV, Roberts DD, Segal IH, Etzler ME (1992) Characterization of the adenine binding sites of two Dolichos biflorus lectins. Biochemistry 31:6938-6942

Gibson DM, Stack S, Krell K, House J (1982) A comparison of soybean agglutinin in cultivars resistant and susceptible to Phytophthora megasperma var. sojae (race 1). Plant Physiol 70:560-566

Gibson KE, Kobayashi H, Walker GC (2008) Molecular determinants of a symbiotic chronic infection. Annu Rev Genet 42:413-441

Giollant M, Guilot J, Damez M, Dusser M, Didier P, Didier E (1993) Characterization of a lectin from Lactarius deterrimus. Research on the possible involvement of the fungal lectin between mushroom and spruce during the early stages of mycorrhizae formation. Plant Physiol 101:513-522

Gouget A, Senchou V, Govers F, Sanson A, Barre A, Rougé P, LontLexica R, Canut H (2006) Lectin receptor kinases participate in protein-protein interactions to mediate plasma membrane-cell wall adhesions in Arabidopsis. Plant Physiol 140:81-90

Hamblin J, Kent SP (1973) Possible role of phytohemagglutinin in Phaseolus vulgaris L. Nat New Biol 245:28-30

Hawes MC, Brigham LA, Wen F, Woo HH, Zhu Y (1998) Function of root border cells in plant health: pioneers in the rhizosphere. Annu Rev Phytopathol 36:311-327

He XJ, Zhang ZG, Yan DQ, Zhang JS, Chen SY (2004) A salt-responsive receptor-like kinase gene regulated by the ethylene signaling pathway encodes a plasma membrane serine/threonine kinase. Theor Appl Genet 109:377-383

Herman EM, Hankin CM, Shannon LM (1988) Bark and leaf lectins of Sophora japonica are sequestered in protein-storage vacuoles. Plant Physiol 86:1027-1031

Hervé C, Dabos P, Galaud J-P, Rougé P, Lescure B (1996) Characterization of an Arabidopsis thaliana gene that defines a new class of plant receptor-kinases with an extracellular lectin-like domain. J Mol Biol 258:778-788

Hirsch AM (1999) Role of lectins (and rhizobial exopolysaccharides) in legume nodulation. Curr Opin Plant Biol 2:320-326

Hirsch AM (2004) Plant-microbe symbioses: a continuum from commensalism to parasitism. Symbiosis 37:345-363

Janeway CA Jr (1989) Approaching the asymptote? Evolution and revolution in immunology. Cold Spring Harb Symp Quant Biol 54:1-13

Jones JD, Dangl JL (2006) The plant immune system. Nature 444:323329

Kalsi G, Etzler ME (2000) Localization of a Nod factor-binding protein in legume roots and factors influencing its distribution and expression. Plant Physiol 124:1039-1048

Kanzaki H, Saitoh H, Takahashi Y, Berberich T, Ito A, Kamoun S, Terauchi R (2008) NbLRK1, a lectin-like receptor kinase protein of Nicotiana benthamiana, interacts with Phytophthora infestans INF1 elicitin and mediates INF1-induced cell death. Planta 228:977-987

Kardailsky IV, Sherrier DJ, Brewin NJ (1996) Identification of a new pea gene, PsNlec1, encoding a lectin-like glycoprotein isolated from the symbiosis of root nodules. Plant Physiol 111:49-60

Kijne JW, Bauchrowitz MA, Díaz CL (1997) Root lectins and rhizobia. Plant Physiol 115:869-873 
Komath SS, Kavitha M, Swamy MJ (2006) Beyond carbohydrate binding: new directions in plant lectin research. Org Biomol Chem 4:973-988

Larkin MA, Blackshields G, Brown NP, Chenna R, McGettigan PA, McWilliam H, Valentin F, Wallace IM, Wilm A, Lopez R, Thompson JD, Gibson TJ, Higgins DG (2007) Clustal W and Clustal X version 2.0. Bioinformatics 23:2947-2948

Leborgne-Castel N, Lherminier J, Der C, Fromentin J, Houot V, Simon-Plas F (2008) The plant defense elicitor cryptogein stimulates clathrin-mediated endocytosis correlated with reactive oxygen species production in bright yellow-2 tobacco cells. Plant Physiol 46:1255-1266

Lefebvre B, Furt F, Hartmann MA, Michaelson LV, Carde JP, Sargueil-Boiron F, Rossignol M, Napier JA, Cullimore J, Bessoule JJ, Mongrand S (2007) Characterization of lipid rafts from Medicago truncatula root plasma membranes: a proteomic study reveals the presence of a raft-associated redox system. Plant Physiol 144:402-418

Lerner DR, Raikhel NV (1992) The gene for stinging nettle lectin (Urtica dioica agglutinin) encodes both a lectin and a chitinase. J Biol Chem 267:11085-11091

Lioi L, Galasso I, Santantonio M, Lanave C, Bollini R, Sparvoli F (2006) Lectin gene sequences and species relationships among cultivated legumes. Genet Resour Crop Evol 53:1615-1623

Lord JM (1985) The structure and synthesis of plant lectins. Tansley Rev No 3. New Phytol 101:351-366

Loris R, Casset F, Bouckaert J, Pletinckx J, Dao-Thi MH, Poortmans F, Imberty A, Perez S, Wyns L (1994) The monosaccharide binding site of lentil lectin: an X-ray and molecular modelling study. Glycoconj J 11:507-517

Mandaci S, Dobres MS (1993) Sequence of a vegetative homolog of the pea seed lectin gene. Plant Physiol 103:663-664

Martínez Zamora MG, Castagnaro AP, Díaz Ricci JC (2008) Genetic diversity of Pto-like serine/threonine kinase disease resistance genes in cultivated and wild strawberries. Mol Evol 67:211-221

McAlvin CB, Stacey G (2005) Transgenic expression of the soybean apyrase in Lotus japonicus enhances nodulation. Plant Physiol 137:1456-1462

McMahon SA, Miller JL, Lawton JA, Kerkow DE, Hodes A, MartiRenom MA, Doulatov S, Narayanan E, Sali A, Miller JF, Ghosh $\mathrm{P}$ (2005) The C-type lectin fold as an evolutionary solution for massive sequence variation. Nat Struct Mol Biol 12:886-892

Melander M, Ahman I, Kamnert I, Strömdahl AC (2003) Pea lectin expressed transgenically in oilseed rape reduces growth rate of pollen beetle larvae. Transgenic Res 12:555-567

Meyer D, Pajonk S, Micali C, O'Connell R, Schulze-Lefert P (2008) Extracellular transport and integration of plant secretory proteins into pathogen-induced cell wall compartments. Plant J. doi:10.1111/j.1365-313X.2008.03743.x

Mirelman DE, Galun E, Sharon N, Lotan R (1975) Inhibition of fungal growth by wheat germ agglutinin. Nature 256:414-416

Mishkind ML, Raikhel NV, Palevitz BA, Keegstra K (1982) Immunocytochemical localization of wheat germ agglutinin in wheat. J Cell Biol 92:753-764

Mishkind ML, Palevitz BA, Raikhel NV, Keegstra K (1983) Localization of wheat germ agglutinin-like lectins in various species of the Gramineae. Science 220:1290-1292

Moreno FBMB, de Oliveira TM, Martil DE, Vicoti MM, Bezerra GA, Abrego JRB, Cavada BS, Filgueira de Azevedo W Jr (2008) Identification of a new quaternary association for legume lectins. J Struct Biol 161:133-143

Nagadhara D, Ramesh S, Pasalu IC, Rao YK, Sarma NP, Reddy VD, Rao KV (2004) Transgenic rice plants expressing the snowdrop lectin gene (gna) exhibit high-level resistance to the whitebacked planthopper (Sogatella furcifera). Theor Appl Genet 109:13991405
Navarro-Gochicoa M-T, Camut S, Timmers ACJ, Niebel A, Hervé C, Boutet E, Bono J-J, Imberty A, Cullimore JV (2003) Characterization of four lectin-like receptor kinases expressed in roots of Medicago truncatula. Structure, location, regulation of expression, and potential role in the symbiosis of Sinorhizobium meliloti. Plant Physiol 133:1893-1910

Oldroyd GED, Downie JA (2008) Coordinating nodule morphogenesis with rhizobial infection in legumes. Annu Rev Plant Biol 59:519 546

Pettersen EF, Goddard TD, Huang CC, Couch GS, Greenblatt DM, Meng EC, Ferrin TE (2004) UCSF Chimera-a visualization system for exploratory research and analysis. J Comput Chem 25:1605-1612

Peumans WJ, van Damme EJM (1995) Lectins as plant defense proteins. Plant Physiol 109:347-353

Pull SP, Pueppke SG, Hymowitz T, Orf JH (1978) Soybean lines lacking the 120, 000-Dalton seed lectin. Science 200:1177-1179

Pusztai A (1991) Plant lectins. Cambridge University Press, Cambridge

Roberts DD, Goldstein IJ (1983) Hydrophobic binding properties of the lectin from lima beans (Phaseolus lunatus). J Biol Chem 257:11274-11277

Roberts NJ, Brigham J, Wu B, Murphy JB, Volpin H, Phillips DA, Etzler ME (1999) A Nod factor-binding lectin is a member of a distinct class of apyrases that may be unique to legumes. Mol Gen Genet 262:261-267

Robinson MJ, Sancho D, Slack EC, LeibundGut-Landmann S, Reis e Sousa C (2006) Myeloid C-type lectins in innate immunity. Nat Immunol 7:1258-1265

Robledo M, Jiménez-Zurdo JI, Velázquez E, Trujillo ME, ZurdoPiñeiro JL, Ramírez-Bahena MH, Ramos B, Díaz-Mínguez JM, Dazzo F, Martínez-Molina E, Mateos PF (2008) Rhizobium cellulase CelC2 is essential for primary symbiotic infection of legume host roots. Proc Natl Acad Sci USA 105:7064-7069

Sadeghi A, Smagghe G, Broeders S, Hernalsteens JP, De Greve H, Peumans WJ, Van Damme EJM (2003) Ectopically expressed leaf and bulb lectins from garlic (Allium sativum L.) protein transgenic tobacco plants against cotton leafworm (Spodoptera littoralis). Transgenic Res 17:9-18

Sasabe M, Naito K, Suenaga H, Ikeda T, Toyoda K, Inagaki Y, Shiraishi T, Ichinose Y (2007) Elicitin-responsive lectin-like receptor kinase genes in BY-2 cells. DNA Seq 18:152-159

Sato S, Nakamura Y, Kaneko T et al. (2008) Genome structure of the legume, Lotus japonicus. DNA Res. doi:10.1083/dnares/dsn008

Schmid M, Davison TS, Henz SR, Pape UJ, Demar M, Vingron M, Schölkopf B, Weigel D, Lohmann JU (2005) A gene expression map of Arabidopsis thaliana development. Nat Genet 37:501-506

Schnell DJ, Etzler ME (1988) cDNA cloning, primary structure and in vitro biosynthesis of the DB5 lectin from Dolichos biflorus. J Biol Chem 263:14648-14653

Shahidi-Noghabi S, Van Damme EJ, Smagghe G (2008) Carbohydrate-binding activity of the type-2 ribosome-inactivating protein SNA-I from elderberry (Sambucus nigra) is a determining factor for its insecticidal activity. Phytochemistry 69:2972-2978

Sharon N (1993) Lectin-carbohydrate complexes of plants and animals: an atomic view. Trends Biochem Sci 18:221-226

Sharon N, Lis H (1989) Lectins as cell recognition molecules. Science 246:227-234

Sharon N, Lis H (1990) Legume lectins-a large family of homologous proteins. FASEB J 4:3198-3208

Sharon N, Lis H (2004) History of lectins: from hemagglutinins to biological recognition molecules. Glycobiology 14:53R-62R

Sreevidya VS, Hernandez-Oane RJ, So RB, Sullia SB, Stacey G, Ladha JK, Reddy PM (2005) Expression of the legume symbiotic lectin genes psl and gs52 promotes rhizobial colonization of roots in rice. Plant Sci 169:726-736 
Valot B, Dieu M, Recorbet G, Rais M, Gianinazzi S, Dumas-Gaudot E (2005) Identification of membrane-associated proteins regulated by the arbuscular symbiosis. Plant Mol Biol 59:565-580

Van Damme EJM, Barre A, Rougé P, Van Leuven F, Peumans WJ (1995a) The seed lectins of black locust (Robinia pseudoacacia) are encoded by two genes which differ from the bark lectin genes. Plant Mol Biol 29:1197-1210

Van Damme EJM, Barre A, Smeets K, Torrekens S, Van Leuven F, Rougé P, Peumans WJ (1995b) The bark of Robinia pseudoacacia contains a complex mixture of lectins. Plant Physiol 107:833843

Van Damme EJM, Barre A, Rougé P, Peumans WJ (2004) Cytoplasmic/ nuclear plant lectins: a new story. Trends Plant Sci 9:484-489

Van Damme EJM, Nausicaa L, Peumans WJ (2008) Plant Lectins. In: Kader JC, Delseny M (eds) Advances in botanical research, vol 48. Elsevier Ltd, San Diego, pp 107-209

Van Eijsden RR, Díaz CL, De Pater BS, Kijne JW (1995) Sugar-binding activity of pea (Pisum sativum) lectin is essential for heterologous infection of transgenic white clover hairy roots by Rhizobium leguminosarum biovar viciae. Plant Mol Biol 29:431439

van Rhijn P, Fang Y, Galili S, Shaul O, Atzmon N, Winiger S, Eshead Y, Lum M, Li Y, To V, Fujishige N, Kapulnik Y, Hirsch AM (1997) Expression of early nodulin genes in alfalfa mycorrhizae indicates that signal transduction pathways used in forming arbuscular mycorrhizae and Rhizobium-induced nodules may be conserved. Proc Natl Acad Sci USA 94:5467-5472

van Rhijn P, Goldberg RB, Hirsch AM (1998) Lotus corniculatus nodulation specificity is changed by the presence of a soybean lectin gene. Plant Cell 10:1233-1250

van Rhijn P, Fujishige NA, Lim P-O, Hirsch AM (2001) Sugar-binding activity of pea (Pisum sativum) lectin is essential for heterologous infection of transgenic alfalfa (Medicago sativa L.) plants by
Rhizobium leguminosarum biovar viciae. Plant Physiol 125:133144

Varki A, Cummings RD, Esko JD, Freeze HH, Stanley P, Bertozzi CR, Hart GW, Etzler ME (eds) (2008) Essentials of glycobiology. Cold Spring Harbor Laboratory Press, New York, pp 375-481

Venable A, Mitalipova M, Lyons I, Jones K, Shin S, Pierce M, Stice S (2005) Lectin binding profiles of SSEA-4 enriched, pluripotent human embryonic stem cell surfaces. BMC Dev Biol 5:15. doi:10.1186/1471-213X-5-15

Vijayan M, Chandra N (1999) Lectins. Curr Opin Struct Biol 9:707-714

Vitale A, Bollini R (1995) Legume storage proteins. In: Kigel J, Galili $\mathrm{G}$ (eds) Seed development and germination. Dekker M Inc, New York, pp 73-102

Wan J, Patel A, Mathieu M, Kim SY, Xu D, Stacey G (2008) A lectin receptor-like kinase is required for pollen development in Arabidopsis. Plant Mol Biol 67:469-482

Wearne K, Winter HC, O'Shea K, Goldstein IJ (2006) Use of lectins for probing differentiated human embryonic stem cells for carbohydrates. Glycobiology 16:981-990

Wen F, VanEtten HD, Tsaprailis G, Hawes MC (2007) Extracellular proteins in Pisum sativum L. root tip and border cell exudates. Plant Physiol 143:773-783

Wulf A, Manthey K, Doll J, Perlick AM, Linke B, Bekel T, Meyer F, Franken P, Küster H, Krajinski F (2003) Transcriptional changes in response to arbuscular mycorrhiza development in the model plant Medicago truncatula. Mol Plant Microbe Interact 16:306-314

Xia B, Kawar ZS, Ju T, Alvarez RA, Sachdev GP, Cummings RD (2005) Versatile fluorescent derivatization of glycans for glycomic analysis. Nat Methods 2:845-850

Zipfel C (2008) Pattern-recognition receptors in plant innate immunity. Curr Opin Immunol 20:10-16

Zmasek CM, Eddy SR (2001) ATV: display and manipulation of annotated phylogenetic trees. Bioinformatics 17:383-384 